the intervals of respirations if possible up to ten. A slight amount of skill enters into this method in rapidly pouring out and enumerating the drops, and also an element of judgement in estimating the depth of the respirations, for although deep respirations, which are generally forcible, tend to take up a diminished percentage of vapour this tendency is insufficiently marked to prevent a more rapid evaporation, so that a shorter interval has to be allowed, that is, about four respirations; and, conversely, as many as eight or nine shallow respirations may be required to make up an interval. However, these adjustments are made with little difficulty, for a change of anaesthetic state, which is conveniently gradual, will call attention to the requirements. Chloroform given in this way is administered under the most favourable conditions regarding distribution, quantity, and temperature variations, and it is capable of the most delicate double adjustment by drops and intervals; in fact, once a routine is established, the vapour is practically continuously constant in strength; thus, with the artificial respiration apparatus I obtain values of $3.15,3.2$, and 3.2 per cent. at the seventeenth, twenty-third, and twenty-eighth respiration respectively.

As regards the frame employed, I find a Schimmelbusch with a pear-shaped rim to be the most readily adaptable. An efficient drop bottle is also an essential, and nothing is better than a glass bottle with a grooved stopper affording a rapid succession of individual drops, of which between 40 and 50 go to make up $1 \mathrm{c.cm}$.

The above procedures, derived from experimental work and clinically confirmed, I believe to be the best suited to the administration of pure chloroform.

I may shortly state that these principles relating to the process of "breathing through" apply with added force to the use of diluted chloroform, as in the form of A.C.E. mixture; it is only necessary to employ a cover of four-fold gauze divided into four equal divisions and to proceed on an assumed efficiency of one-third of that of pure chloroform-that is to say, using three times the quantity. With ether anaesthesia may be very readily maintained in this way without undue waste (it may, indeed, be induced with a little perseverance), and the excellence of the type of anaesthesia thus obtained deserves detailed comment; however, clinical considerations are somewhat outside the scope of this paper and cannot be further discussed. I think I have said enough to show how the principles can be extended in many directions.

In this paper I have considered the administration of anaesthetics from one point of view only-that is, that of the regulation of the vapour. This is an essential part of the anaesthetist's business, and I am inclined to think that it is the most essential part, for no accurate or intelligent appreciation of the physiological effects of anaesthetics is possible without it.

I have to conclude with an expression of thanks to Professor Vaughan Harley for kindly allowing me the use of his laboratory.

1 Holmes's Surgery, vol. iii, third edition. 2 Lancet, July, 1904 3 Waller and Geets, British Medical Journal, 1903; Waller and Collingwood, Proc. Physiol. Soc., 1903; Levy, Proc. Physiol. Soc., 1904. 27 th, 1905 , p. 1415.

\section{LANDRY'S PARALYSIS.}

ERIC MACNAMARA, and JULIUS BERNSTEIN,
assistant Physician,
weStMINSTER hospital.

THE case of which full details are given below was from a clinical standpoint a typical instance of Landry's disease. The motor symptoms, it should be noted, were those of a gradually-ascending flaccid palsy, and these mounted to so high a level that on the eleventh day of illness ocular movements were impaired. Thereafter the symptoms gradually retrograded. Throughout there were no sensory symptoms nor any incontinence of faeces or urine, and eventually recovery was complete.

W. H., aged 30, waiter, admitted to the Westminster Hospital on August 3rd, 1904.

Previous History. - Had had syphilis at 24 , and thereafter thorough and prolonged treatment. Had had no other previous serious illness. Had not drunk to excess. Usually smoked 1 oz. of tobacco a day.

History of Present Illness.-Quite well up till eleven days before admission; at that time the legs began to get weak, and in three days' time loss of power in them was complete. For three days before admission patient had been gradually losing power in the hands, and for one day had had double vision and difficulty in swallowing. For first three days of his illness patient's legs had ached. There had been no numbness or paraesthesia, and no headache or backache. The bowels had been constipated, and there had been some difficulty in starting micturition. There had been no incontinence.

State on Admission.-The patient was well nourished and of a good colour. Mentally he was markedly intelligent. Special senses of smell, taste, and hearing were normal. Vision of R. eye $\frac{6}{24}$, of $L$. ${ }^{6} 8$. Visual fields were normal. Optic discs normal.

Outward movements of both eyes were incomplete in range. There was no nystagmus. The left pupil was a little larger than the right, and both were almost immobile to bright light. There was slight ptosis of the left eyelid. There was no obvious affection of parts supplied by the fifth and seventh obvious affection of parts supplied by the fifth and seventh
nerves. The left half of the soft palate drooped more than the nerves. The left half of the soft pald

The tip of the tongue on protrusion deviated to the right and its lateral movements were feeble. There was slight difficulty in pronouncing the lingual and guttural sounds.

There was no movement at any of the joints of the legs or feet, with the exception of the right first metatarso-phalangeal joint; here the big toe could be feebly flexed and extended. The leg, if lifted and dropped, fell flaccidly and presented no passive resistance to the movement of its joints.

The patient could not sit up though the abdominal muscles could be felt to contract on his attempting to do so. The movements of the upper extremity were very feeble. The thumbs and little fingers could not be approximated, and the fingers scarcely abducted or adducted.

Flexion of the head was very feebly performed, but lateral movements of the head were fair. Respiratory movements were good. The anal sphincter was very lax.

There was nowhere any sign of tremor, fibrillation, or rigidity. The various muscles felt flabby, but did not seem to be wasted. The co-ordination of movements, where any could be performed, was good.

There were no sensory changes, objective or subjective. No reflexes could be obtained from the lower limbs. The abdominal, cremasteric, and epigastric superficial reflexes were normal, as were also the triceps and supinator jerks. There were no trophic or spinal changes.

A faint apical systolic murmur was heard, but otherwise the thoracic and abdominal organs presented no abnormal physical signs. The spleen was not enlarged. The urine showed no abnormality.

Progress.-Up to August 8th the movements of the limbs and trunk remained much as described above. On that day the emotional movements on the left side of the face were noted to be not quite so good as on the right side; forced movements were equal on the two sides. The ptosis of the left eyelid was more pronounced. The abdomen was rather distended. On August 10th the hand grips were slightly stronger and speech a little more distinct. The patient complained less of diplopia. The left pupil reacted to light more rapidly than the right. Both pupils just reacted to painful stimulathan the right. Both pupils just reacted to painful stimulation of the skin of the neck, but did not accommodate. The
triceps and wrist jerks were less brisk than before. The triceps and wrist jerks were less brisk than before. The
abdominal, cremasteric, and epigastric reflexes could not be elicited.

By August 15th the patient was again able to swallow solids, the ocular movements were better, and the hand grips still stronger.

On August 25th slight power of flexion and extension at the ankles returned; the legs, also, could be slightly flexed upon the trunk and abducted and adducted.

By September 3rd both pupils reacted well and equally. There was no ptosjs, and ocular movements were through a normal range, but there was a little nystagmus on extreme lateral movement. There was no further complaint of diplopia. The patient could sit up in bed, using his arms to heave himself up. All movements at all the joints of the legs could be feebly performed. The knee-jerks and ankle-jerks seemed normal. The flexor response was present on both sides.

Result. - By september 17th the patient was walking with the help of sticks, and shortly after left the hospital.

The temperafure had been observed to be elevated to $99.4^{\circ} \mathrm{F}$. The temperature had been observed to be elevated to $99.4^{\circ} \mathrm{F}$.
on the day of his admission, thereafter it had been normal. on the day of his admission, thereafter it had been normal. On Augast 9th the electrical reactions were reported as show-
ing some diminution to faradism, and on September 14th some ing some diminution to faradism, and on September 14th some
increase. There was no reaction of degeneration. Drug treatment had consisted in the administration, during the early stages, of potassium iodide. From August 21st onwards massage and electricity were used. The patient was last seen in May, 1904, when he had almost wholly recovered. He could then walk perfectly well on the flat, but experienced a little difficulty in going upstairs.

REMARKS.

The etiology of those cases of acute ascending palsy which appear to their various repcrters to justify the title 
of Landry's disease covers a wide field. Among the causes are chronic alcoholism, though this condition is regarded rather as predisposing than exciting (Andr. Schultz, ${ }^{1}$ LeviSirugue, ${ }^{2}$ Mills and Spiller, ${ }^{3}$ Bailey and Ewing, ${ }^{4}$ Ormerod, ${ }^{5}$ Colla ${ }^{6}{ }^{6}$ and Prince $^{7}$ ); syphilis (Landry, ${ }^{\circ}$ Levi-Sirugue, ${ }^{2}$ Diller, ${ }^{9}$ Alexander, ${ }^{10}$ Vizioli, ${ }^{11}$ Ross ${ }^{12}$ ); influenza (LeviSirugue,${ }^{2}$ Krewer ${ }^{13}$ Ballet, ${ }^{14}$ Galetta,${ }^{15}$ James and Fleming ${ }^{16}$ Ormerod, ${ }^{5}$ Pick ${ }^{17}$ ), and some others of the acute specific diseases; enteric (Levi-Sirugue, ${ }^{2}$ Girandeau et Levi, ${ }^{18}$ Curschman ${ }^{19}$ ), variola (Levi-Sirugue, ${ }^{2}$ Oettinger et Marinesco, ${ }^{20}$ Bernhardt $\left.{ }^{21}\right)$; varicella, measles, pneumonia (Levi-Sirugue ${ }^{2}$ ); malaria (Taylor and Clark, ${ }^{22}$ Baumstock, ${ }^{23}$ and Remlinger ${ }^{2 t}$ ); tuberculosis (Westphal ${ }^{25}$ ); diphtheria (Westphal ${ }^{25}$ ); and gonorrhoea (Mills and Spiller, ${ }^{3}$ Ricaldoni and Lamas, ${ }^{26}$ Landry $\left.{ }^{\circ}\right)$; cold (Landry, ${ }^{\gamma}$ Levi-Sirugue, ${ }^{2}$ Jaccoud, ${ }^{2 \tau}$ Watson ${ }^{2 \gamma}$ ); prolonged exertion (Parhon, ${ }^{29}$ Ormerod ${ }^{5}$ ); nervous fatigue, tobacco, venereal excess, and heredity have each been suggested as possible causes. The disease has been associated with dysmenorrhoea (Landry ${ }^{\text {)}}$, parturition, and attempted abortion: (Spiller ${ }^{30}$ Levi-Sirugue ${ }^{2}$ ) with accidents of catheterism and cystitis (Walker ${ }^{31}$ ); with gastric trouble ( (Roux $^{32}$ ); with auto-intoxication (Kapper, ${ }^{33}$ Levi-Sirugue ${ }^{2}$ ); with anaemia (Schwab $\left.{ }^{31}\right)$; with septicaemia (Oppenheim ${ }^{35}$ ); with exophthalmic goître (Rosenfeld ${ }^{16}$ ); and with antirabic treatment (Rendu et Roux ${ }^{37}$ ). Rissler ${ }^{38}$ has described an epidemic of the disease, while Erball ${ }^{39}$ thinks it may be a sporadic form of beri-beri.

In other reported cases there does not seem to have been anything in the histories of the patients which could be adduced as having any etiological bearing on the malady. In the case of the patient whose history is given above, the only noteworthy facts in this connexion are that he had syphilis six years previously (but for this he had, according to the present canons of our art, been well treated) and that he smoked $1 \mathrm{oz}$. of tobacco daily.

Several micro-organisms have been noted by various observers as occurring in the tissues of patients. A diplococcus resembling Weichselbaum's has been described by Piccinino, ${ }^{40}$ and was found by him in the spinal cord, and similar organisms have been found by Dercum ${ }^{41}$ in the cerebro-spinal fluid and by Buzzard and Russell ${ }^{42}$ in the exudation upon the meninges and in the substance of the cord. Dercum's case was, however, described as one of acute poliomyelitis, and Buzzard and Russell's was one of acute ascending meningo-myelitis.

A micro-organism like the pneumococcus was found in the blood from the heart of a case, but not in or about the spinal cord, by Roger and Josué, ${ }^{43}$ and similar organisms were found in the spinal fluid, and, mixed with bacilli, in the spinal cord by Courmont and Bonne.44 Streptococcus was found by Oettinger and Marinesco, ${ }^{20}$ in the cord by Remlinger, ${ }^{24}$ and with staphylococei by Jaccoud. ${ }^{27}$ A bacillus was found by Baumgarte ${ }^{45}$ in the blood and medulla and in the veins, but not in the spinal cord, by Centanni. ${ }^{46}$ A bacillus, "voisin du proteus," was found by Chantemesse and Ramond, ${ }^{47}$ Eberth's bacillus by Curschman $^{19}$ and Levi-Sirugue. ${ }^{2}$ Staphylococcus was found in a sciatic and in the spleen by Eisenlohr, ${ }^{48}$ and a bacillus like that of anthrax by Marie and Marinesco ${ }^{49}$ Lastly, a tetracoccus has been described by Farquhar Buzzard. $^{50}$ In the patient W. H. lumbar puncture was performed and a tetracoccus discovered in the spinal fluid, as recounted below.

Numerous other observers have found no microorganism after death; Courmont and Bonne ${ }^{44}$ found none in the blood drawn during life, and Knapp and Thomas ${ }^{5}$ found none in spinal fluid drawn during life. In experiments on animals Roger and Josue $e^{43}$ produced paraplegia in mice and rabbits by the injection of their pneumococcuslike organism ; a similar organism found and injected by Courmont and Bonne ${ }^{4+}$ produced no results. F. Buzzard's ${ }^{50}$ tetracoccus on injection produced a rapidlyspreading palsy. The tetracoccus found in the case of $\mathrm{W} . \mathrm{H}$. produced no results on injection, as recounted below.

So numerous are the supposed etiological factors that it is plain either that many conditions can produce the disease or that, so far, the causa causans has not been definitely determined. It is remarkable in how many cases reported in quite recent years it has been impossible to name any etiological factor or, by the most approved bacteriological methods, to obtain any micro-organism from the tissues of patients having the disease.
The SyMptoms.

Dealing next with symptoms, it is obvious that the collection of symptoms known as Landry's disease has a sufficient individuality of its own and occurs with sufficient frequency to justify Landry's action in placing it in a special position by itself. But from that collection there are divergencies of greater or lesser moment. Some are so great that it is difficult to follow how the various diagnosticians have managed to place their cases in this category: others so small that it is difficult, without splitting hairs, to remove the cases from this category. A few of such divergences are here referred to.

In a case of Prince ${ }^{\tau}$ the patient was found paralysed in his arms and legs one hour after he had been seen to use them. Sensation and sphincters were normal and death occurred in twelve hours. In a case of Taylor and Waterman ${ }^{52}$ flaccid palsy of arms and legs occurred contemporaneously and nineteen days later respiratory difficulty commenced and resulted in death in two days. Ricaldoni and Lamas ${ }^{26}$ tell of a case which began with tingling and loss of power in the right hand and later similar symptoms in the left hand and legs. In this case there was pain on pressing the muscles and hyperaesthesia of the hands and feet. Knapp and Thomas il report a case which commenced with cramps in the abdomen and legs. In Taylor and Clark's ${ }^{22}$ case the disease began with pain in the back, numbness below the level of the umbilicus and fibrillary tremors were shortly afterwards observed. Schwab's ${ }^{35}$ case began with numbness in the hands eight weeks before death. This was shortly followed by an ascending and gradually increasing loss of power Wappenschmidt's ${ }^{79}$ case first showed bulbar symptoms. Guizetti, ${ }^{53}$ Howard ${ }^{54}$ Rowden ${ }^{53}$ and Janichevsky ${ }^{56}$ report similar cases. In a fatal case of Hirtz and Lesne ${ }^{50}$ the symptoms did not ascend as far as the bulb.

Diller ${ }^{9}$ tells of a case in which five weeks after onset much weakness and softness of the muscles remained and R.D. was demonstrated. Vizioli's ${ }^{11}$ case began with severe pain, succeeded by loss of power, fibrillary twitchings, and R.D. Levi-Sirugue, ${ }^{2}$ Oppenheim, ${ }^{35}$ and Raymond, ${ }^{57}$ say that R.D. may occur. Girandeau and Levi ${ }^{18}$ in their case could get no reaction to faradism.

Sensory symptoms are described in the majority of cases, and in general consist of numbness and tingling with, less frequently, objective anaesthesia. In Galetta's ${ }^{13}$ case there was severe pain in the sacral region, and in Marie and Marinesco's ${ }^{19}$ pain was intense over the whole body. Oppenheim ${ }^{35}$ states that pain is exceptional.

The sphincters, according to Landry's ${ }^{8}$ description, in almost all cases remain normal ; in Oettinger and Marinesco's, ${ }^{20}$ in Courmont and Bonne's, ${ }^{4 t}$ in Girandeau and Levi's, ${ }^{18}$ in Schwab's, ${ }^{34}$ and in two cases of Knapp and Thomas $^{51}$ the sphincters were involved. Fever is unusual, but occurred in the cases of Knapp and Thomas, ${ }^{51}$ Taylor and Clark, ${ }^{22}$ and Brissaud. ${ }^{61}$ In Eisenlohr's ${ }^{18}$ case the patient had had some fever three weeks before the symptoms came on.

\section{Prognosis.}

Though prognosis has been considered grave in this disease favourable terminations have been frequently reported. Nearnow, ${ }^{59}$ Soltman, ${ }^{60}$ Brissaud, $^{61}$ Parhon, ${ }^{29}$ Foley, ${ }^{62}$ Knapp and Thomas, ${ }^{51}$ Baumstock, ${ }^{23}$ and Spiller, ${ }^{30}$ have all seen complete recoveries in their cases. In the cases of Muratow ${ }^{63}$ and Senna, ${ }^{64}$ which were reported as cases of Landry's disease, recovery occurred in the first, but in the second there was only great improvement. In Muratow's case, however, one of the signs was ankle clonus, and in Senna's there was tenderness of nerve trunks and muscles. Martinet ${ }^{65}$ reports two cases in which the first stage was that of acute ascending palsy, the second that of amyotrophy, and the third that of progression to complete recovery. Raymond ${ }^{57}$ mentions a somewhat similar case.

It is, on the whole, a striking fact that in those cases which, clinically speaking, were cases of Landry's disease, recovery, when it occurred, was complete. On the other hand, partial and very tardy recovery only seems to have occurred in those cases which can only hesitatingly be brought under the heading of Landry's disease.

The case of W. H. was most typically, clinically speaking, one of Landry's disease. The motor symptoms were those of a gradually ascending flaccid palsy, and had mounted to so high a level that on the eleventh day of illness ocular movements were impaired. Thereafter, the 
symptoms gradually retrograded. There were no sensory symptoms, and there was no incontinence of urine or faeces.

Morbid Anatomy.

Before proceeding to discuss the morbid anatomy of Landry's disease, it is desirable to consider if there are other diseases having a similar clinical course, and whose anatomy is known. Here a difficulty at once confronts us, for some authors, on discovering a gross lesion of the cord, put aside a diagnosis of Landry's disease. To a certain extent they are justified, for it is a fact that Landry's own words, in his first description of the disease, are that there is "an absence of all appreciable nervous lesion." Methods of examination have, however, improved since Landry's time, and nervous lesions inappreciable then are obvious now. Un the other hand are observers who seem ready to persist in a diagnosis of Landry's disease, even when the post-mortem appearances are very decidedly those of a very obvious myelitis or neuritis. Indeed, for the present, it would appear that a case which clinically has been one of Landry's disease, and which post mortem presents, let us suppose, some slight change in the grey matter of the cord, may be classified as a poliomyelitis or as Landry's disease according to the fancy of the observer. E. W. Taylor, ${ }^{66}$ in a paper on Poliomyelitis of the Adult, describes the typical course of the disease as a more or less extensive palsy which is rapid in onset and which tends to recover, the sensory symptoms being slight and transitory. He speaks of how reporters of cases of Landry's disease describe "lesions essentially characteristic of poliomyelitis, and yet classify their cases under the vague heading of Landry's paralysis."

The-following have reported cases clinically like Landry's disease and anatomically poliomyelitis : Cornil and Lepine, ${ }^{67}$ Niedner, ${ }^{63}$ Rissler, ${ }^{38}$ Jagie, $^{69}$ Schultze, ${ }^{70}$ Dercum, ${ }^{41}$ Dauber, ${ }^{83}$ Goldscheider, ${ }^{4 \$}$ and Redlich. ${ }^{85}$ Sherman and Spiller ${ }^{71}$ report a case of poliencephalomyelitis which ran a clinical course as of Landry's disease.

In other cases, again, where clinically the cases were Landry's disease, changes found post mortem were confined to the nerves (Dejerine and Goetz, ${ }^{72}$ Vierordt, ${ }^{73}$ Roth, ${ }^{74}$ Nauwerck and Barth, ${ }^{75}$ Pribykow $\left.{ }^{i 6}\right)$. In Putnam's ${ }^{i 7}$ and Eisenlohr's ${ }^{4 y}$ cases, in which the only lesions found were in the nerves, there were, in addition to the symptoms of acute ascending palsy, tenderness and pains which suggested a neuritis.

Is there, then, any change or want of change which from an anatomical point of view takes Landry's disease out of the categories of neuritis of a special clinical type or of poliomyelitis of a special clinical type?

To endeavour to answer this question is to endeavour to ascertain what changes have been discovered in cases of Landry's disease. In a case of $\mathrm{Hun}^{73}$ there was a slight cerebro-spinal meningitis and degeneration of the anterior roots of the cauda equina, and in one of Courmont and Bonne ${ }^{44}$ there was oedema of the cerebral meninges and signs of desquamation of some of the cells in the cord itself. Vascular lesions have often been noted. Hirtz and Lesnes $e^{58}$ described enlargement of the calibre of the vessels and thickening and infiltration of their walls along the whole length of the cord. Remlinger ${ }^{24}$ describes inflammation in the central branches of the anterior spinal artery. Bailey and Ewing $^{4}$ and Wappenschmidt ${ }^{79}$ describe intense perivascular infiltration. Taylor and Waterman ${ }^{52}$ observed, in one case of theirs, some vascular congestion, but nothing else. In Schwab's ${ }^{3 \downarrow}$ case there was capillary engorgement of the cord and meninges and some haemorrhages into the nervous substance. Immermann, ${ }^{80}$ as well as perivascular infiltration, noted hyaline deposits. and this has also been observed $b_{y}$ Taylor and Clark, ${ }^{22}$ Klebs, ${ }^{81}$ and Baumgarten. ${ }^{45}$

In many cases, besides perivascular infiltration, there is more or less extensive alteration of the cells of the grey matter (Iwanow, ${ }^{82}$ James and Fleming, ${ }^{16}$ Chalvet, ${ }^{86}$ Schulz and Schultze, ${ }^{87}$ von Rencz, ${ }^{83}$ Ross, ${ }^{89}$ Marie and Marinesco, ${ }^{49}$ and Roussel ${ }^{90}$ ). Farquhar Buzzard's ${ }^{50}$ case showed minute haemorrhages, changes in the ganglion cells of the grey matter, and degenerative changes in the myelin sheaths. Changes of an even more extensive character are frequently reported. Mills and Spiller, ${ }^{3}$ Knapp and Thomas, ${ }^{51}$ Wilson and Rothrock, ${ }^{91} \mathrm{~J}$. W. Thomas, ${ }^{92}$ Hoffmann, ${ }^{93}$ Ballet, ${ }^{14}$ Rissler, ${ }^{38}$ and Eichberg ${ }^{94}$ have observed changes in the cells of the grey matter, and, in the same cases, changes in the nerves. Levi-Sirugue ${ }^{2}$ described $^{-}$ "small disseminated areas of softening along the whole length of the cord." Dejerine ${ }^{95}$ described hypertrophy of the axis cylinders in the white matter, fragmentation of the myelin, and karyokinesis of the neuroglia. Oettinger and Marinesco ${ }^{20}$ and Jaccoud ${ }^{27}$ have also had cases in which there were areas of softening in the dorso-Jumbar region of the cord.

In a certain number of cases cerebral lesions have been found with lesions of the cord and nerves. Worcester ${ }^{96}$. observed changes in the anterior cornual cells, peripheral nerves, and cerebral cortex. Sherman and Spiller ${ }^{72}$ case was clinically one of Landry's disease, and anatomically a poliencephalomyelitis. Bailey and Ewing ${ }^{4}$ describe a similar case. Ballet and Dutil ${ }^{97}$ in their case found in the brain periarterial and perivenous nodules with pericapillary infiltration, and in the cord changes in the cells of the grey matter. Goebel ${ }^{9 \star}$ found vascular extravasation in the medulla, with disappearance of nuclei and fatty degeneration of fibres. He also found degeneration of the fibres in some muscles. Lastly, hyperplastic splenitis has often been observed (Kahler and Pic, ${ }^{39}$ Bernhardt, ${ }^{21}$ Westphal, ${ }^{25}$ Putnam, ${ }^{77}$ Remlinger, ${ }^{21}$ Guizetti $^{53}$ ).

So far, then, an examination of the polymorphic changes found does not suggest a constancy of type which justifies, from the anatomical point of view alone, the removal of Landry's disease to a separate category. The broad facts that emerge are that the changes found suggest a. recent origin and an inflammatory cause.

We are next met with the rather startling fact that in certain cases no changes whatsoever have been met with post mortem. Landry himself said there was an absence of all appreciable nervous change, and other observers, later in time and of fuller knowledge, have said the same. Schultz ${ }^{1}$ in a case of acute ascending palsy in 1898 found no anatomical alteration. The same was the case with Girandeau and Levi ${ }^{1 \times}$ in 1898, Taylor ${ }^{100}$ in 1898 , Ormerod $^{5}$ in 1892, Albu ${ }^{101}$ in 1893. Kapper ${ }^{33}$ in 1900. Greppin $^{102}$ in 1892, Watson ${ }^{28}$ in 1892 , Leube ${ }^{103}$ in 1893, and with Prince ${ }^{7}$ in 1895 . Less recent observers who found nothing are Bernhardt ${ }^{21}$ and Westphal. ${ }^{25}$ Dixon Mann ${ }^{104}$ found no changes in the cord, but the nerves in his case were not examined.

On the balance, however, it is obvious that changes are usually present, and as time goes on tend more and more to be noted. The cases which show no morbid appearance may perhaps be analogous to those severe forms of the acute specifics which kill from the intensity of the toxaemia and even before the proper symptoms of the disease have had time to display themselves. But it is evident that it would be, at present, a little rash to prognosticate what anatomical changes will be found in a case of acute ascending palsy or, conversely, on a post-mortem inspection of the nervous system from such a case to say what the symptoms had been.

But though the details of our knowledge of the anatomy of Landry's disease require considerable elaboration, a general survey of the disease, as one of rapid onset. running a short course and eventuating in death or in complete recovery, with post-mortem appearances suggesting recent inflammation and toxaemia, reminds us of the. characteristics of the acute specifics. Not, however, until one of the numerous micro-organisms found by various reporters has been more definitely connected with the disease does it seem possible that we shall be able finally to classify Landry's disease in this category. For the first. time, so far as I know, a micro-organism was found in spinal fluid extracted during life by lumbar puncture in the case of W. H. That organism resembles the onefound by Farquhar Buzzard, and a description is detailed below.

I am indebted to Drs. Murrell, Gossage, and Abrahams, who were successively in charge of the case during the summer holidays, for permission to publish it.

\section{REMARKS BY DR. BERNSTEIN.} BaCteriological Examination.

A. Cerebro-spinal Fluid-Several c.cm. of fluid were obtained hr lumbar puncture on August 5 th and inoculated into a tube containing peptone bouillon and incubated at 28० $\mathrm{C}$. Three days later the broth was turbid from the presence of C. Three days later the broth was turbid from the presence of cocci of variable size, shape, and arrangement, which
stained with I,oeffler's metbylene blue and retained the stain in stained with I,oeffler's metbylene blue and retained the stain in
Gram's method. These were arranged in pairs, tetrads, a few groups, and short chains. The results of subcultures were as 
follows: (1) In bouillon there appeared in a few days a white, slimy, viscid deposit at the bottom of the tube of a growth resembling the original culture; (2) on agar fine colonies appeared, somewhat resembling streptococci, but more closely aggregated, and consisting of cocci arranged in pairs, tetrads, and small groups; (3) a gelatine stab in four days and these slowly increased in size without liquefaction or gas formation. From the agar growth subcultures were again cormation. From the agar growth subcultures were again made in broth, with results as in (1) above, with which it was Eyre and Price Jones intracranially with the centrifugalized culture, but after many weeks, no symptoms ensuing, the animals were killed. No pathological changes or micro-
organisms were found in the central nervous system or its membranes.

B. Blood. - On August 6 th the skin over the antecubital fossa was sterilized and one of the veins exposed by a small
incision; $10 \mathrm{c.cm}$. of blood were removed aseptically and immediately. transferred to three flasks of peptone bouillon and incubated at $38^{\circ} \mathrm{C}$. In fourteen hours no organisms could be found in Flask $A$, and two days later all the media was still clear. Four days later, that is, six days after inoculation, the bouillon in Flask $B$ showed a faint cloudiness. This on examination was shown to be due to a growth of cocci of rather large size generally grouped as tetrads, staining with ordinary dyes and not decolori

1. In bouillon in tbree days a slimy, viscid deposit at the bottom of the tube similar to the subcultures from the cerebrospinal fluid, this consisted of cocci arranged in tetrads, pairs, and a few short chains which were generally Gram-staining, but in places one or two cocci were partially decolorised by this method. The individual cocci in some groups varied in size.

2 In a gelatine shake culture in three days numerous scattered minute colonies without liquefaction or gas formation. These only increased very slightly in size after several weeks' growth.

3. On agar in three days minute closely-aggregated colonies resembling the corresponding subcultures from the cerebrospinal fluid.

Flask $\mathrm{C}$ was examined eight days after inoculation, and contained a few cocci arranged in groups, tetrads, diplococci. and short chains of three. The staining reactions and subcultures were identical with those described above, but the cocci in the subcultures appeared to be slightly larger than in the original culture. These subcultures seemed more luxuriant than any of the previous ones, a fact that was noted in further subcultures.

Thus from the blood and cerebro-spinal fluid during the acute stage of disease was isolated a micrococcus which arranged itself most frequently as a tetrad, was Gram-staining, and which gave somewhat characteristic growths in bouillon and in gelatine, where it grew as an anaërobe without liquefaction. Against its being a contamination are the facts that the fluids were taken on different days, yet produced similar results, a pure culture of the same organism was found in all the media, and this organism was of slow growth in the parent cultures. In all our similar experiments with the blood from infective disorders, where contamination has occurred the growth has been verv rapid, generally of a mixed nature, and where an organism has been isolated from the blood in pure culture the positive results have been confirmed by finding the -organism in tbe lesions after death, and in the spleen in many cases. In a few cases which have recovered, somewhat confirmatory evidence has been obtained by agglutination tests, which, unfortunately, were not performed in this case. Wherever our results have been negative, the resulting history has confirmed the absence of organisms; and so the evidence is in favour of the organism being present in the body of the patient. The patient recovered, so the infection cannot be regarded as a terminal one.

The organism bears some resemblance to the tetracoccus isolated post mortem from a case of Landry's paralysis by Buzzard. This, however, did not stain by Gram's method in the original cultures though it did in subcultures, and several of our cocci at times behaved erratically with Gram's method. We were not as successful even as Buzzard in our animal experiments, but this negative result loses much in value when it is remembered that subcultures were used for inoculation, and in these the cocci were rapidly changing their character, as evidenced by the increasing luxuriance of growth in the successive subcultures compared with the slow growth of the original cultures.

No attempts were made to exalt the virulence of the organism owing to the difficulties arising in connexion with animal experiments. The cocci were still alive after several months' storage in the cool chamber.

Conclusion.

Hence we can only conclude that an organism resembling a tetracoccus isolated from a similar case post mortem was existing in an active condition in the blood and cerebro-spinal fluid of a patient with Landry's paralysis, from which he recovered. And though the evidence is insufficient to definitely point to it as the causal agent, in the light of bacteriological findings in other acute infections the association is suggested. Further, it helps to confirm Buzzard's post-mortem findings in a similar case.

We are much indebted to Drs. Eyre and Price Jones for their kindness in performing the animal inoculations, and to $\mathrm{Dr}$. Hebb for his kind advice and valuable suggestions.

1 Andr. Schultz, Norzk. MERE AND BIBIIOGRAPHY.

1898. Journ of Nervous and Mental Dis., p. 365, 1898. 4 Bailey and Spiller, New York Medical Journ., July, 1896. 5 Ormerod, st. Bart. Hosp. Rep., p. 137, 1892. 6 Colla, Il Morgagni, p. 669, 1899. 7 Prince. Journ. of
Nervous and Mental Dis., p. 686, 1895. 8 1 Landry, Gaz. Hebdomadaire, Juill. 29th and Août 5th, 1859. 98 Diller, Journ. of Nervous and Mental Dis., October, 1902; and Amer. Med, p. 747, 1904. 10 Alexander, Syphilis und Auge, Wiesbadeu, 1889. 1i Vizioli, Ann. di Nevrol., 1899. 12 Ross, Treatise on Peripheral Neuritis, p. 16, 1893. 13 Krewer, Zeitschrift für

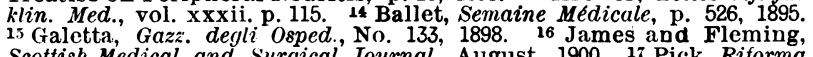
Scottish Medical and Surgical Journal, August, 1900.17 Pick, Riforma Medica, p. 310, vol. iv, 1901. 18 Girandeau et, Levi, Revue Neurologique,
October 15th, 1898. 19 Curschman, Verhandlungen des V. Congresses f. October 15th, 1898. 19 Curschman, Verhandlungen des V. Congresses f.'
innere Medicin. p. 473, 1896. ¿0 Oettinger et Marinesco, Soc. Méd. des innere Medicin. p. 473, 1896. 00 Oettinger et Marinesco, Soc. Méd. des
Hoppitaux, p. 63, 1895. 21 Bernliardt, Berlin. klin. Woch., p. 561, 1871.

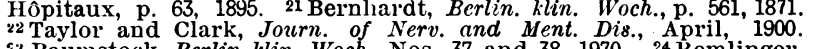

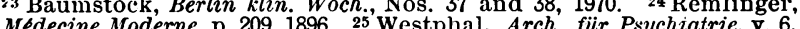

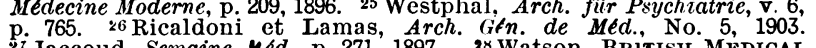
JourNat, p. 1286, 1892. 29 Parhon, Bull. Soc. Silud. in Med., 1900. ${ }^{80}$ Spiller, Journ of Nerv. and Ment. Dis., vol. xxvii, p 454 . 31 Walker, Jancet, March 11th, 1905. 32 Roux. Gaz. Irebdom., p. 793,1896. 33 Kapper, Weiner klin. Woch., p. 153, 1900 . 34 Schwab, Journ. of Nerv. and Ment.
Dis. December, 1900 . 85 Oppenheim, Lehrbuch der Nervenkrank., p. 400 , Dis., December, 1900 . \$5 Oppenheim, Lehrbuch der Nervenkrank., p. 400 ,
V. xi. 36 Rosenfeld, Berlin. klin. Woch., June 9th, 1902 . 37 Rendu et Roux, Presse Med., No. 259, 1897. 38 Rissler, Nord. Med. Arkiv., p. 22 , 1888. ${ }^{39}$ Erbell, Norsk. Mag. fiir Laegevidenskaben, p. 629, 1899 and Ment. Dis., p. 116, vol. xxvii. 42 Buzzard and Russell, Clinical Soc. Trans., vol. xxxi. 43 Roger et Josué Presse Med., No. 62, 45 Baumgarten, Arch. der Heilkunde, 1876.46 Centanni, Ziegler' Beiträge zur path. Anat. V, viii. 1890 , 47 Chantemesse et Ramond, Soc. de Biol., July 23rd, i898. 48 Eisenlohr. Deutsche med. Woch. p. 841, 1890. 49 Marie et Marinesco, Soc. Méd. des Hôpitaux. p. 659, 1895. so Buzzard, Farquhar, Brain. p. 94, 1903. 51 Knapp and Thomas, Journ. of Nervous and Mental Dis., February, 1900. 52 T'aylor and Waterman,
Boston Med. and Surg. Journ., December 25tl, 1902. 533 Guizetti, Roston Med. and Surg. Journ., December 25tl, 1902 . 53 Guizett,
Rivista Speriment. di Freniat.. vol. xxv. p. 509. 54 Howard, BRITIS

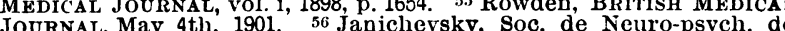
JoURNAI, May 4th. 1901. 56 Janichersky, Soc. de Neuro-psych. do Systeme Nerveux., Deuxiéme Series. $58 \mathrm{Hirtz}$ and Lesné, Presse Méd Systeme Nerveux., Deuxiemow, Obozre, jepish. p. 151, No. 2, 1899. co Solt-

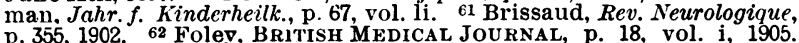
63 Mulatow, Soc. of Neurologists of MOScow, January, 1892. 64 , Senna

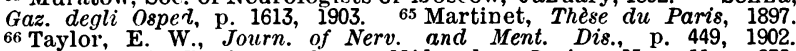
66 Taylor, E. W., Journ. of Nerv. and Ment. Dis., p. 449, 1902.

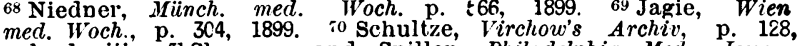
med. Woch., p. . $_{11}$ Sherman and Spiller. Philadelphin Med. journ, vol. 734. 1900. 72 Dejerine and Goetz, Arch. de Physinl., p. 312, 1876.

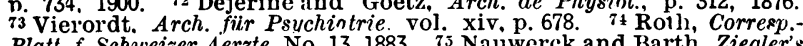

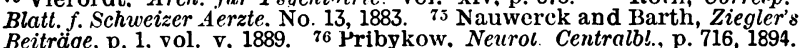
i7 Putnam, Boston ifed. and Surg. Journ., p. 159, 1889 . 78 Hun, Neu York Med. Journ., p. 20.1891 . 79 Wappenschmidt, Deut. Zeitsch. f. Nervenheil., p. 306. $1900 .{ }^{80}$ Immermann, Neurolog. Cevitralbl., p. 384, 189c.
s1 Klebs, Deut. med. Woch., p. 81, 1891. 8: Iwanow, St. Petersburgh med. ${ }^{81}$ Klebs, Deut. med. Woch., p. 81, 1891. 83 Iwanow, St. Petersburgh med.
Woch., p. 393. 1888. 83 Dauber. Deut. Zeitsch f. Nervenh, p. 200. 1893. Woch, p. 393. 1888. 83 Dauber. Deut. Zeitsch f. Nervenh, p. 200. 1893.
81 Goldacheider. Zeit. f. klin. Med., p. 494, 1893. 85 Redlich, Wien. kli" Woch., p. 287, $1894 .{ }^{86}$ Chalvet, Gaz. des Hôp. de Paris, No. 93, 1871
87 Schulz and Schultze, Archiv f. Psychiatrie, vol. xii, p. 456. 88 Von

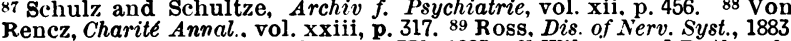
Ro Roussel, Arch. de Med. Nav, p. 370. 1883. 9i Wilson and Rothrock, Philadelphia Ared. Journ, p. 1181, 1898. 92 Thomas, J. W. Antherican Joum of Med. Sc. August, 1898 93 Hoffmann, Arch. fuir Psychiatric,

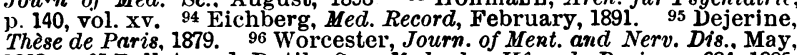
1898. 97 Ballet and Dutil, Soc. Med. des Hop. de Paris. p. 684, 1895 98 Goebel, Miinch. med. Woch., No. 30, 1898. 99 Kahler and Pic, Arch.f

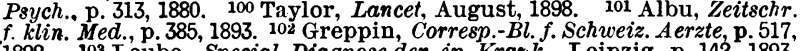
1892.103 Leube, Specinl Diagnose der in Krank., Leipzig. p. 142,1893 104 Dixon Mann, Med. Chron., May, 1887 . et on den Velden, Deutsches
Arch.f. kl. Med., p. 333, vol. xix. Pitres et Vaillard, Arch. de Physiol, p. Arch.f. P8ych., p. 339, 1883. Erb, Arch.f. Psych., p. 758, 1874. Steiner, Med. Soc of Budapest, January, 1896 . Vranjican, Wien. klin. Woch,
p. 485, 1895. Bramwell, F.. Rev. of Neurol. and Pych., May, 1c05. p. 485, 1895. Bramwell, F.. Rev. of Neurol. and Psych., May, $1 \mathrm{co5}$. Med. A s8oc., May 14th, 1904 . Vincent, Arch. de Med. Exper. et d'Anat. Palh. 1893. Rolly, Minch. med. Woch., Nos. 30 and 31, 1903. Behrend, Deut. med. Woch., p. 775, 1895. Cramer, Certralbl. f. Allg. Poth. u. Path. Anat., Robinson, Med. Rec., p. 534. vol. xlvii. Howard, BRITISH MEDICAI. JOURNAL, p. 1654, vol. i, 1898. Griffith, Lancet, p. 1490, vol. ii, 1000 . Seurol. $u$. Psych., p. 406,1900 . Sci, p. 36, vol. Cxx. Dydynski. Johr. über
Nicht, Virchow's Archiv, p. 265, vol lxix. Hlawa, Arch. Bolismes de Med. p. 256 vol. iv. Mouravieff and Montourine, Revue Russe de Med., 1902. Babinski and Charrin, Soc.
de Biologie, p. 257, 1888. Phisalix and Charrin, Soc. de Biologie, No. 3, 1898. Boinet, Gaz. des Hopitaux, May 2nd, 1899. Levy, Pellegrinn Archiv. Generral, p. 132, 1865. Ketli, Wien. med. Blatt., p. 250 , 1887.

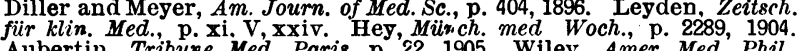
Aubertin. Tribuxe Med. Paris, p. 22, 1905. Wiley, A Amer. Med. Phil., p. 359, 1905. Diller and Billard, Am. Med.. p. 747. 1904. Donarth, 
p. I197, v. vi. Gordinier, Albany Med. Ann., p. 56, 1904. Simmons, N. Orleans Med. and Surg. Journ., p. 517, 1903. Warmington, Liverp onl Med. Chir. Journ. p. 261, 1903. Mvrée, Finska täk-sällsk handl., p. 49 , p. 348, 1904. Tuley, Med. Journ., Louisville, p. 112, 1904.

\section{NOTES ON A CASE OF FISSURA ABDOMINALIS :}

OPERATION AT AGE OF $2 \frac{1}{2}$ HOURS.*

By HOWARD ST́EVENSON, B.A., M.B., F.R.C.S., SURGEON, ULSTER HOSPITAL FOR WOMEN AND CHILDREN.

THE comparative rarity of a case of this type coming to operation, and the apparent recovery from the immediate effects of operative interference, are the reasons why I thought fit to report the case.

The subject was a seven to eight months premature female child, born before the arrival of Dr. Ferguson on. June 5 th.

When I saw the child two hours later a large mass of bowe lay exposed outside the abdomen without peritoneal or other covering. On washing the bowel with warm saline solution it was seen that the prolapse consisted of all the large inte was Meckel's diver ticulum. A part of the bowel was covered by the gelatinous matter of the umbilical cord, a well-marked line indicatin where it joined the skin. Close to the right of the base of the umbilicus, and joined to it by the gelatinous matter, was the orifice of the patent diverticulum. This diverticulum was about 2 in. in length, its diameter that of a cedar pencil, and joined the small intestine about 3 in. from its termination.

I removed the diverticulum flush with the bowel, and excised the rest of the gelatinous matter, freeing the umbilical cord at the same time from the margin of the fissure. The cord at the same time from the margin of the fissure. The slightly enlarged towards the pubes, and the intestines placed within the abdomen. The deep layers of the abdominal wall within the abdomen. The deep layers of the abdominal wall
were united by continuous catgut suture, and the skin by several points of silkworm gut, the umbilical cord being fixed in the upper angle of the wound. The child was slightly sick after the operation, but rallied well, and four hours after was fed with $3 j$ of milk and 3 iij of water; this was repeated ever six hours. The following day a rectal catheter was passed and (1) olive oil was administered by the mouth but had no effect, so a small simple enema was given, with satisfactory result. The bowels subsequently acted naturally. There was no difficulty with micturition.

The diet was increased on the third day, the child still seeming hungry and taking well. The stitches were removed on the fifth day, when the wound was soundly healed; no signs of distension were present. On the sixth day, however, the child became jaundiced and passed a clay-coloured motion, and some purpuric spots appeared on the lower extremities. It was somewhat listless and did not enjoy its food as before. It died on the evening of the eighth day.

I confess to being disappointed in the result, but feel that, could the child have been returned to its mother and had the advantages of breast feeding and animal warmth, it would probably have survived, as it never exhibited an abdominal symptom and seemed to be progressing satisfactorily until the sixth day.

I have not been able to find much information in the literature, but would refer to a case recorded by $\mathrm{Mr}$. Lockhart Mummery ${ }^{\text {; }}$ it was not operated on and died. In Mr. Edmund Owen's work on the Surgical Diseases of Children an excellent photograph and remarks on treatment appear.

1 British Journal of Children's Diseases, 1907.

\section{ASCARIS LUMBRICOIDES AS CAUSE OF APPENDICITIS.}

By ALDO CASTELLANI, M.D.,

DIRECTOR, CLINIC FOR TROPICAL DISEASES, COLOMBO.

IN a very interesting paper published in the BrITISH Medical Journal of March 26th, 1906, Dr. F. E. Anley has suggested the hypothesis that $A$ scaris lumbricoides might be the cause of some cases of appendicitis-particularly in the tropics where that worm is so common. In support of his theory Dr. Anley quotes two cases in which the symptoms of the disease subsided when a round worm was passed in the stools. He is of opinion that the inflammation might be set up by the worm attempting to

\footnotetext{
* Read at the annual meeting of the Ulster Branch of the British
} Medioal Association, June 21st, 1906. enter the appendix or by the worm obtaining a partial entrance, if no more, into the organ.

Nearly two years ago I had the opportunity of making in Ceylon a post-mortem examination which seems to me to prove that Dr. Anley's supposition is in some cases an actual fact.

The body was that of a young Tamil girl of about 14 years of age. The clinical history sent with the body was unfortunatel not very complete, but the following principal points could be gathered. The girl had been suffering from intestinal helminthiasis for a long time and had passed round worms in the stools on several occasions. She was given santonin. Shortly after the administration of the drug she had vomiting, pain and tenderness on the abdomen, especially on the right iliac fossa, with some rise of temperature. This condition lasted apparently unchanged for about two days, when the girl died suddenly.

The post-mortem examination was held a few hours after death. There was nothing to be noted concerning the thoracic organs. There was no effusion into the peritoneal cavity, and the peritoneum did not show any sign of inflammation.

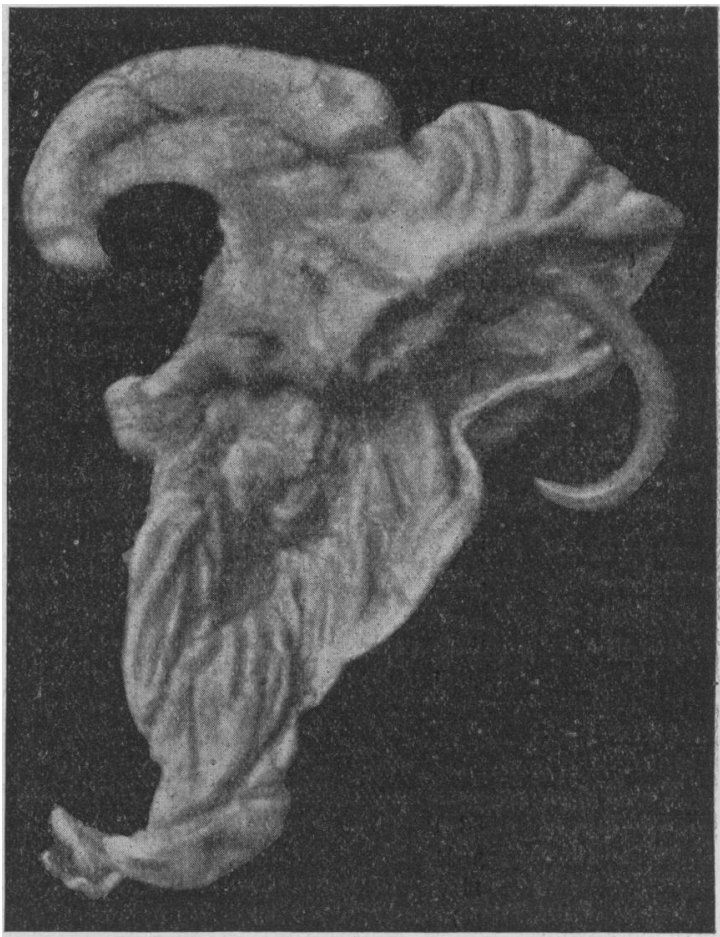

The appendix was observed to be protruding, and presented engorged superficial vessels, and here and there small areas of fibrinous exudation. The organ was quite free, no adhesions whatever being present. To the touch it was hard, and felt as if it contained a cylindrical body. The intestine having been opened, this body was seen to be an ascaris firmly imbedded for about one half of its length in the appendix, the other half being free in the intestine. The worm was very firmly inserted into the appendix and could not be pulled out, into the appendix, and although some pently dead, as the free portion did not show any movements. On squeezing the appendix towards the base a little purulent liquid oozed from between the walls of the appendix and the ascaris. This liquid was examined bacteriologically; the $B$. coli only was found The small intestine contained numerous ascarides, some of which were still alive. No other helminths were present. The mucosa of the small and large intestine was slightly hyperaemic, but no ulcers of any kind were present; the mesenteric gland were not enlarged.

It might be said that the worm entered the appendix after the death of the patient; it seems to me that this cannot have been the case, as the worm was very firmly imbedded, and was dead when the examination was made.

A photograph of the appendix containing the worm was taken, and is here given. Later on sections of a portion of the appendix were examined microscopically. They showed a diffuse leucocytic infiltration of all the coats; the mucosa was swollen, and several minute haemorrhages were seen. The lumen was completely occupied by the worm, the external surface of which was surrounded by a zone of desquamated and exudated cells from the mucosa, which showed several erosions.

In conclusion, it appears to me that the result of this post-mortem examination clearly proves that ascarides 